\title{
LA MULTIMODALIDAD EN LA NARRATIVA ESPAÑOLA CONTEMPORÁNEA: TRES VÍAS DE INTEGRACIÓN DEL DISCURSO NO VERBAL
}

\author{
MULTIMODALITY IN CONTEMPORARY SPANISH NARRATIVE: \\ THREE WAYS OF INTEGRATING THE NON-VERBAL DISCOURSE
}

\author{
Rodrigo GUIJARRO LASHERAS \\ Universidad Complutense de Madrid \\ rguijarr@ucm.es
}

\begin{abstract}
Resumen: Este artículo propone un acercamiento a la multimodalidad en los estudios literarios desde una doble perspectiva: en primer lugar, introduce el concepto en el análisis de la narrativa española contemporánea; en segundo lugar, argumenta la relevancia que poseen en la construcción del sentido del texto tres vías poco exploradas de interacción entre el discurso verbal y los otros modos semióticos presentes en la obra. Estas se caracterizan respectivamente por la aparente redundancia, desconexión o contradicción que implican.
\end{abstract}

Palabras clave: Multimodalidad. Narrativa española contemporánea. Discurso no verbal. Imágenes en el texto.

Abstract: This paper proposes an approach to multimodality within literary studies from a two-fold perspective: first, it introduces the concept of multimodality in the field of contemporary Spanish narrative; second, it 
studies three ways in which the verbal discourse and other semiotic modes can interact with each other within a novel. These have been usually put aside due respectively to their apparent redundancy, lack of connection, or contradiction.

Key Words: Multimodality. Contemporary Spanish narrative. Nonverbal discourse, Images within the text.

\section{INTRODUCCIÓN}

La historia de la literatura es un catálogo de novedades. Estas son las que jalonan sus diversos capítulos, las que generan crisis y cambios de paradigma y las que a menudo acaparan mayor atención crítica. Una innovación incuestionable a la que venimos asistiendo desde hace décadas en la narrativa española es la proliferación, cada vez más acusada, de lo que en este trabajo se denomina novela multimodal. Dicho en breve, es multimodal toda aquella novela que incluye elementos no textuales como parte constitutiva de sí misma, toda aquella en la que participan dos o más modos semióticos. Se trata de un concepto proveniente de la lingüística y de reciente implantación en los estudios literarios (el primero en hacerlo fue Hallet, 2009) ${ }^{1}$ que no ha sido explorado en el ámbito de la literatura en español. Este artículo tiene, entonces, dos objetivos principales: en primer lugar, mostrar que la novela española no está al margen de esta tendencia y que su estudio contribuye a una mejor comprensión de la multimodalidad. Para ello, en segundo lugar, y a través de un corpus inexplorado desde esta perspectiva, me planteo mostrar tres posibilidades de interacción multimodal que parecen suponer un estorbo o un choque para la integración

\footnotetext{
${ }^{1}$ En realidad, Hallet (2008) desarrolla ya la idea de la novela multimodal en un artículo publicado en lengua alemana un año antes, en 2008, si bien el que supuso la difusión del concepto y el que suele ser citado como primer aldabonazo para el estudio de este tipo de novela es el artículo de 2009.
} 
de los diversos modos semióticos de los que se compone la novela, ya sea porque la multimodalidad parezca en primera instancia superflua, porque se desarrolle de manera paralela e independiente, o porque contradiga o socave el discurso verbal. Dado que se trata de una noción no muy desarrollada en este marco de análisis, comienzo analizando algunos problemas conceptuales que plantea la multimodalidad para, en la segunda sección, trazar un breve recorrido introductorio por el cultivo que este tipo de escritura ha tenido en la literatura española. Finalmente, las tres secciones subsiguientes analizan las tres formas de interacción multimodal aparentemente poco integrada en el texto que ya se han mencionado y que permiten ampliar el marco de análisis existente.

\section{EL CONCEPTO DE MULTIMODALIDAD: HISTORIA Y ALGUNOS PROBLEMAS}

El término multimodalidad surge en los años 90 en el ámbito de la lingüística y de la semiótica social, si bien no alcanza una difusión e implantación generalizadas hasta la década siguiente. El monográfico de Kress y van Leuween (2001) suele considerarse como una de las referencias clave para la consolidación del concepto, al que han seguido innumerables publicaciones, entre las que destacan recientemente los libros de Kress (2009), Jewitt (ed.) (2014), Jewitt, Bezemer y O’Halloran (2016) y Bateman, Wildfeuer y Hiippala (2017). Todos ellos adoptan un enfoque generalista que trata de mostrar el potencial que tiene la multimodalidad aplicada a numerosos campos de las ciencias sociales y las humanidades. Prueba de esta versatilidad es que la editorial Routledge ha creado una serie de Estudios sobre Multimodalidad, en donde ya han visto la luz varios volúmenes que tocan temas sobre didáctica, psicología, informática o marketing, además, claro está, de semiótica y lingüística.

Uno de los terrenos en los que resulta de gran utilidad el análisis multimodal es la literatura. El artículo pionero de Hallet (2009) inauguró el campo, y a este le han seguido Page (ed.) (2010), Doloughan (2011), 
Gibbons (2012 y 2014), Hallet (2015) y Mussetta (2014 y 2016), entre otros. Todos ellos analizan la novela multimodal en el contexto anglosajón y, de forma más eventual, germánico (Sebald principalmente). Pero ¿qué es exactamente una novela multimodal? Multimodal es toda aquella novela que incluya más de un modo semiótico, es decir, más de un "a set of socially and culturally shaped resources for making meaning" (MODE 2012). La novela, por definición, está constituida de lenguaje verbal. La novela multimodal, por tanto, incluye, además de este, otros modos semióticos como imágenes, dibujos, diagramas, mapas, colores, juegos tipográficos y con la disposición espacial del texto, fórmulas matemáticas o partituras - véase la taxonomía a la que Hallet (2009) dedica buena parte de su artículo-. El concepto tiene a su favor que se aplica con facilidad y que los textos aludidos son claramente detectables. Es muy difícil hallar una novela cuya condición multimodal sea objeto de disputa o de duda (otra cuestión es el papel que desempeñe dicho rasgo).

Sin embargo, las complicaciones surgen cuando tomamos en consideración el hecho de que el concepto de modo coexiste en el ámbito de los estudios literarios con el de medio, en el que se basan los estudios sobre intermedialidad — véase Rippl (ed.) (2015) para una panorámica general一. Los teóricos multimodales entienden el medio como "the material form which carries the sign" (MODE 2012), esto es, el libro impreso en papel, en el caso que nos ocupa. Sin embargo, quienes analizan la intermedialidad en distintas manifestaciones artísticas suelen operar con un concepto más amplio del término, entendiendo el medio como "a conventionally distinct means of communication, specified not only by particular channels (or one channel) of communication but also by the use of one or more semiotic systems serving for the transmission of cultural 'messages"' (Wolf, 1999: 35-36). Un medio, entonces, se caracteriza por ser una vía convencionalmente establecida para transmitir mensajes, a través de uno o más canales y de uno o más sistemas semióticos (esto es, modos). El lenguaje verbal sería así un medio, igual que la música, la danza o la pintura. Una fotografía reproducida en una novela, por ejemplo, 
cambiaría de modo pero no de medio, según la primera definición. Para otros autores como Wolf (1999, 2002 y 2013) o Rajewsky (2005), sin embargo, implicaría multimedialidad. Tal vez por ello, en la introducción al Routledge Handbook of Multimodal Analysis, uno de los mayores compendios sobre el tema publicados hasta la fecha, se señala el uso intercambiable que a menudo tienen los términos multimodalidad y multimedialidad (Jewitt, 2014: 11). De ello puede inferirse que la delimitación precisa de estos dos términos fundamentales es un trabajo que todavía está por hacer (Page, 2010: 5), y no es difícil encontrar situaciones de indeterminación entre los modos y los medios que entran en juego.

Asimismo, particularizando ya en la narración literaria, la multimodalidad es un rasgo cualitativo, no cuantitativo. Una novela (o relato) no adquiere el estatuto multimodal a partir de un determinado momento en el que la coexistencia de distintos modos semióticos adquiere un grado de relevancia suficiente. A veces se olvida que el mero hecho de incluir un mapa o un árbol genealógico es ya una práctica multimodal, con independencia de que la implicación del procedimiento de cara a la construcción del sentido de la obra sea menor que en los casos en los que suele recaer la atención crítica (como las de Danielewski, Safran Foer o Haddon). El concepto, no obstante, posee relevancia por la cantidad creciente de novelas multimodales que se ha publicado en los últimos años y por la complejidad también creciente que plantean en lo relativo a la imbricación de distintos modos.

Es necesario trazar dos límites adicionales antes de continuar. En primer lugar, este análisis aborda la novela en formato tradicional, es decir, diseñada para ser editada y leída en papel, pero no las muestras de literatura electrónica o hipernovelas multimedia (también multimodales) que se basan en estructuras solo reproducibles mediante ordenador o algún otro formato electrónico e incorporan, entre otros componentes, vídeo, música o un carácter interactivo. En segundo lugar, es necesario establecer una línea que permita distinguir la novela multimodal del libro ilustrado. Porque ambos son multimodales. El Quijote ilustrado por Doré, 
por ejemplo, es una novela que se edita con imágenes anexas. El libro contiene imágenes. Sin embargo, la obra no; la obra es independiente de estas; las imágenes no forman parte de ella. Podríamos editar el Quijote desprovisto de esas ilustraciones y no estaríamos mutilando o alterando la obra. En el caso de las novelas en las que aquí recae el foco, la supresión de las imágenes sería un fenómeno similar a la eliminación de una oración o un párrafo. Una edición sin imágenes de La tournée de Dios, de Jardiel Poncela, o de cualquiera de las novelas de Manuel Vilas, por ejemplo, constituiría un texto deturpado y el producto resultante no sería, en sentido estricto, ni La tournée de Dios ni una novela de Manuel Vilas. Cuando una novela prexistente se edita con ilustraciones (fenómeno muy en boga durante los últimos años), el libro resultante es multimodal, pero la obra no. En las novelas multimodales, en cambio, las imágenes (o cualquier otro elemento no verbal) son inseparables y constitutivas de la novela; se trata, en suma, de que las ilustraciones no sean ilustrativas; de que no comenten o complementen la obra desde fuera, sino que sean la obra ellas mismas.

\section{ALGUNAS NOTAS SOBRE LA NOVELA MULTIMODAL EN ESPAÑA}

Una primera tesis que este trabajo pretende evidenciar es que la novela multimodal tiene (también) una considerable implantación en la narrativa española. La proliferación, cada vez más acusada, de novelas que incluyen elementos no textuales como parte constitutiva de sí mismas, al mismo nivel que el (resto del) texto es una innovación a la que venimos asistiendo desde hace varias décadas. Es necesario entonces incorporar al análisis multimodal un conjunto importante de textos que hasta ahora no ha contado con ningún estudio monográfico dentro de nuestras fronteras. Uno de los hechos que más interés confiere a esta tendencia es que, como me propongo mostrar, se trata de un fenómeno netamente intergeneracional. No es posible adscribirlo a un grupo, a una estética o a una generación. 
Por otro lado, su proliferación a partir de los años 90, y más aún en lo que llevamos de siglo xxi, no es un producto exclusivo de los cambios que ha generado el advenimiento de la era informática o el avance tecnológico. Es cierto que en las últimas décadas hemos asistido al surgimiento de nuevas posibilidades de edición, reproducción, difusión, lectura y, por tanto, escritura. Pero la convivencia entre texto e imagen es algo muy antiguo, y la inclusión de distintos modos semióticos en una novela también tiene un origen muy anterior. No obstante, no parece desencaminado vincular el auge de la novela multimedial con la primacía que lo visual ha adquirido en el mundo contemporáneo, en donde la información se produce y consume de forma cada vez más frecuente a través de una pantalla. Kress sintetiza esta característica de nuestro tiempo cuando señala "on the one hand, the broad move from the now centuries-long dominance of writing to the dominance of the imagen and, on the other hand, the move from the dominance of the medium of the book to the dominance of the medium of the screen" (Kress, 2003: 1). Por todo ello, a la vez que trazar y rastrear este vínculo entre cultura digital y literatura impresa multimodal, conviene recordar que los árboles genealógicos no escasean en las novelas del siglo xix, que la inclusión de partituras se da en novelas de Goethe o de Balzac, y que obras como Vida y opiniones del caballero Tristam Shandy, de Lawrence Sterne - a menudo considerado como el abuelo de la literatura multimodal-, incluyen ya en el siglo XVIII una gran variedad de recursos multimodales.

En el ámbito español, el fenómeno tampoco es exclusivo de las últimas décadas. Un escritor sistemáticamente multimodal que conviene recordar es Enrique Jardiel Poncela. Su ciclo de cuatro novelas largas, desde Amor se escribe sin hache (1928) hasta La tournée de Dios (1932), explora sistemáticamente las posibilidades que presenta la inclusión incesante de dibujos, esquemas, reproducciones de tarjetas, prensa o juegos tipográficos. En estas obras, la multimodalidad está lejos de ser un mero adorno ilustrativo. Al contrario, está totalmente integrada en la acción narrativa y sirve para hacer que esta avance, incluso en el sentido 
literal de hacer que el tiempo pase.

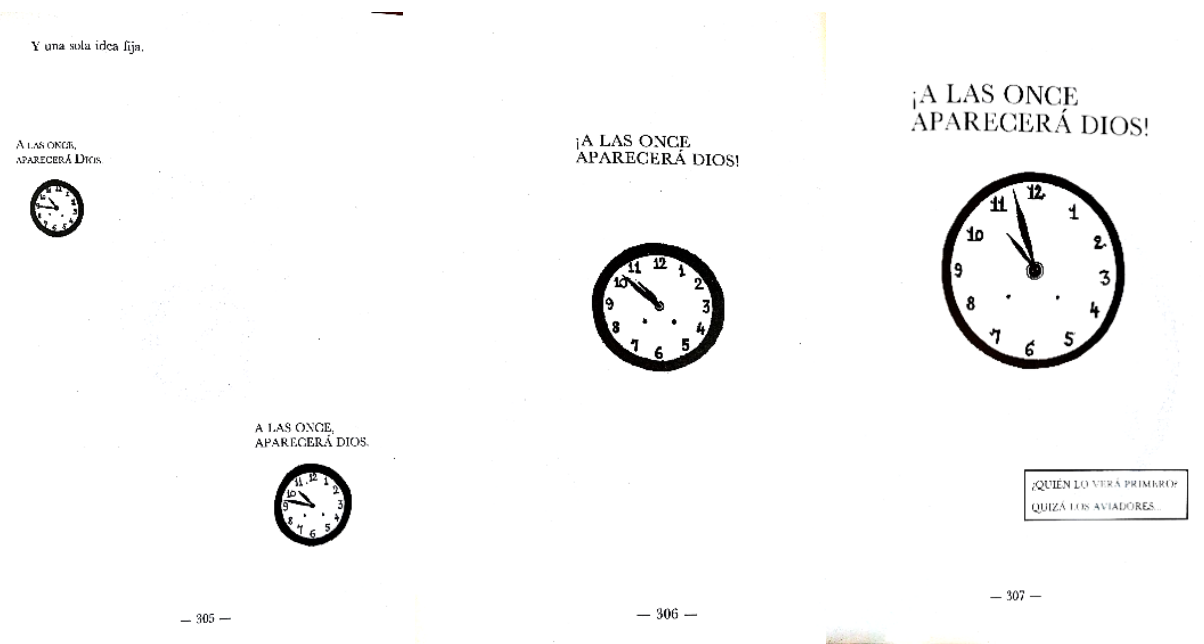

Figura 1. La tournée de Dios, de Enrique Jardiel Poncela (1989: 305-307).

Los relojes de La tournée de Dios son un símbolo particularmente nítido de esto, ya que la historia progresa a través de la concatenación de ellos, que además genera una expectativa creciente paralela al aumento del tamaño de la circunferencia y al avance de las manijas (tal y como se observa en la figura 1). Es, por tanto, un recurso narrativo fundamental para entender la temporalidad del relato. Los juegos tipográficos, a su vez, representan los rasgos prosódicos que el lector debe incorporar al significado verbal de los diálogos. Uno de los personajes deja caer las palabras, que por tanto aparecen dispuestas en caída vertical (Jardiel Poncela, 1989: 148), o pronuncia una afirmación de forma particularmente enfática, lo que se señala únicamente con una tipografía de letra cuatro veces mayor que el resto del texto (Jardiel Poncela, 1989: 257). La oscuridad de un taxi se traslada igualmente a la página (Jardiel Poncela, 1990: 273), o la de un túnel, que interrumpe la narración igual que la visión de los personajes y genera varias páginas totalmente en negro (Jardiel Poncela, 1992: 362365; véase figura 2). Así, el espacio que ocupan las páginas en negro está en relación directa con el tiempo que pasa en la trama, durante el cual 
la conversación de los personajes se detiene. Es decir, el texto imita los acontecimientos de la trama y achaca sus mismos vaivenes: se corta con el paso a nivel (Jardiel Poncela, 1989: 234; véase figura 3), se oscurece con la noche, se interrumpe en un fundido a negro mientras se atraviesa un túnel. La novela no solo narra la trama, sino que la muestra y la lleva a un nivel metanarrativo, generando una inmersión visual en ella.

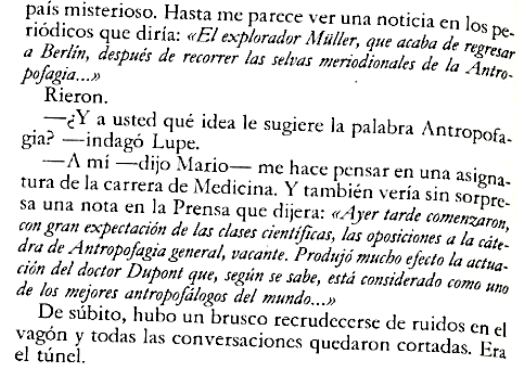

país misterioso. Hasta me parece ver una noticia en los pe-
riódicos que diria: $E$ lexplorador riódicos que diria: "El explorador Miuller, que acaba de regresor a Berlin, después de recorrer las selvas meriodionales de la Antro. pofagia...."

gia? - ¿Y a usted qué idea le sugiere la palabra Antropofa. gia? -indagó Lupe.

tura de la carrera de Medicina Y Y pensar en una asignasa una nota en la Prensa que dijera: $A$ jer tarde comerprecon gran expectación de las clases cientificas, las oposiciones a la cate. dra de Antropofagia general, vacante. Produjo mucbo efecto la actua. ciön del doctor Dupont que, seguin se sabe, está considerado como un. de los mejores antropofálogos del mundo..."

De súbito, hubo un brusco recrudeccrse de ruidos en el vagón y todas las conversaciones quedaron cortadas. Era
el túnel.

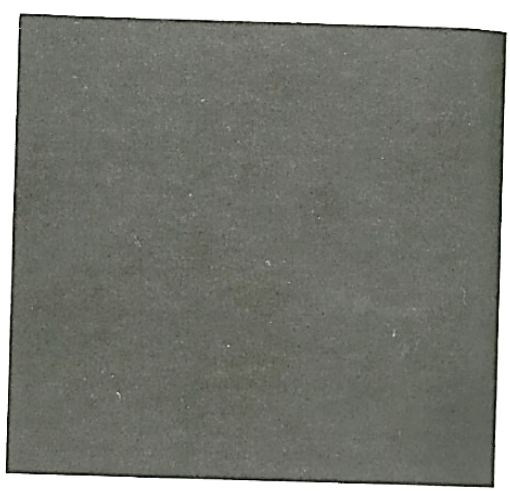

362

metros, cuatro; y el rebaño de acero y de goma recauchutada
vuelve a detenersc.

vuelve a delenersc.
Son las sietc y media de la tarde.

¡NO LLEGAMOS!

A las once de la noche se sigue igual. El rebaño de autos apenas ha adelantado kilómetro y medio. Todo el mundo se desespera. Muchos se han quedado sin gasolina y los que aún tienen les proveen. ¿Generosidad de automovilistas? No. Es que si ellos se quedan allí, los que vienen detrás no podrán pasar adelante.

Empiezan a verse agentes dc circulación. Todos los agentes de circulación de Madrid han sido trasladados a aquel trozo dc carretera, de una docena escasa de kilómetros, y sus caścos blancos despiden destellos lácteos emergiendo de la oscuridad a las zonas de luz.

Nuevo avance, exasperadamente lento. El tumulto ensordece y aturdc. Luz roja. Luz verde.

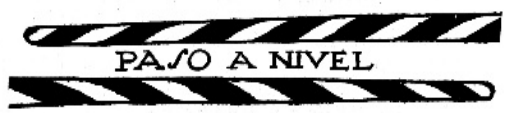

El rebaño de autos lo cruza en desorden, mezclado con los peatones sudorosos, con las bestias de tiro y los animales de montura. Los motores braman ya con verdadera rabia, recalentados por esta marcha inaudita en la que se tarda una hora para recorrer cien metros. Los tubos de escape están al rojo y por entre su humo babean rápidas Ilamas. Los peatones se agarran a las aletas; muchos se suben a los estribos. Los chiquillos cogen picdras y escriben sus nombres en las carrocerías, rayando el duco.

${ }_{-i N i n ̃ o !}$

- iMaldita sea!

- ¡Tu padre!

- Su padre soy yo. ¿Ocurre algo?

Bocinazos. La caravana inmensa salva el paso a nivel

A derecha e izquicrda, en toda la extensión inmensa de los

$$
-234-
$$

Figuras 2 y 3 :

¡Espérame en Siberia, vida mía!, de Enrique Jardiel Poncela (1992: 362) y La tournée de Dios, del mismo autor (Jardiel Poncela, 1989: 234).

Todo ello conlleva sin duda una sorpresa directamente emparentada con el humor propio del autor ${ }^{2}$, para cuyo análisis la multimodalidad es

${ }^{2}$ Es sin duda el rasgo que más se ha estudiado de su producción narrativa y dramatúrgica. 
una clave en la que no se ha reparado lo suficiente. Quizás esto explique también que la multimodalidad sea un recurso difícil de encontrar en novelas serias de ese mismo periodo, lo cual resuena con el prejuicio largo tiempo presente según el cual "works of literature that incorporate graphic elements are low culture artifacts" (Gibbons, 2012: 420).

Además, los recursos multimodales se han empleado en el marco de la novela renovadora o experimental que surgió tras el realismo social a partir de los años 60 (como es bien sabido, las vanguardias históricas hicieron un uso extenso de ellos ${ }^{3}$ ). Algunos de los narradores que reaccionaron con más saña frente al realismo social acudieron a la imagen como una de las vías de experimentación compatibles con una nueva forma de novelar alejada de los presupuestos realistas. José María Guelbenzu lo hace en El mercurio, de 1968, si bien la novela solo cuenta con dos imágenes (Guelbenzu, 1997: 164-165) que representan el movimiento de sendas piernas del protagonista al caminar, ilustrando así su cojera. Y, también, uno de los narradores más irreductiblemente experimentales de la segunda mitad del pasado siglo en el ámbito español, a saber, Julián Ríos. En su obra de referencia, Larva (1983), considerada por muchos como la apoteosis del experimentalismo patrio, Ríos se suma a la nómina de novelistas que recurren a la multimodalidad: puntos sueltos por la página que representan una constelación y que, como en los juegos infantiles, el lector ha de unir para formar una figura, esto es, dotar de sentido, o una página en negro tras un fundido de plomos son algunas de las propuestas visuales (cuya interpretación es tan opaca como el discurso verbal predominante) que contiene la novela.

No obstante, aun con estos y otros precedentes, la década de los 90 puede establecerse como el auténtico punto de despegue de la novela multimodal en España tal y como viene analizándose en estas páginas. Javier Marías publica su primera novela multimodal en 1989 (Todas las almas) y seguirá haciendo uso de este recurso reiteradamente durante los

Véase la reciente monografía de Greco (2014) al respecto.

${ }^{3}$ Gibbons (2012: 423-425) ofrece una sintética aproximación a ello. 
años 90 y hasta la actualidad. Andrés Ibáñez hace lo propio con su primera novela, La música del mundo, en 1995; así como Roberto Bolaño (con Los detectives salvajes, 1998) $)^{4}$, quien, si bien chileno, nombro aquí en la medida en la que, asentado en Barcelona, su obra se publicó mayormente en España. Los ya citados José María Guelbenzu (Esa pared de hielo, 2005) y Julián Ríos (Sombreros para Alicia, 1993) seguirán asimismo incorporando elementos no verbales a sus textos, de igual manera que empiezan a hacerlo Lolita Bosch (Tres historias europeas, 2005), Agustín Fernández Mallo (Trilogía Nocilla, 2006-2009), Manuel Vilas (España, 2008), Vicente Luis Mora (Alba Cromm, 2010), Antonio Orejudo (Un momento de descanso, 2011), Rubén Martín Giráldez (Menos joven, 2012), José María Merino (El río del Edén, 2012), Ramón Buenaventura (NWTY, 2013), Mario Cuenca Sandoval (Los hemisferios, 2014), Javier Cercas (El impostor, 2014), David Trueba (Blitz, 2015), José C. Vales (Cabaret Biarritz, 2015) o Rafael Reig (Señales de humo, 2016) ${ }^{5}$.

Por supuesto, la anterior no pretende ser en ningún caso una nómina completa. Seguramente, cada lector podrá recordar algún ejemplo que no se recoge en estas páginas y que refuerce aún más idea de que estamos ante un fenómeno que cuenta cada vez con más acólitos. Lo que el anterior listado trata de mostrar es el carácter intergeneracional e independiente de escuelas o estéticas que le atribuyo: desde autores que inician su andadura en el experimentalismo (Guelbenzu, Ríos), hasta narradores que logran sus primeros éxitos ya en democracia (Merino, Marías), novelistas próximos a la estética o generación llamada Nocilla (Fernández Mallo, Mora), posmodernos como Vales ${ }^{6}$, u otros con propuestas narrativas tan diferentes

\footnotetext{
${ }^{4}$ La multimodalidad de esta novela sí ha recibido una cierta atención. Véase, por ejemplo, el artículo de Villegas (2012), que se centra en la interpretación de las imágenes con las que de hecho finaliza la obra.

${ }^{5}$ Cito solo una de las primeras novelas destacadas de cada autor en la que aparecen elementos multimodales (no necesariamente la primera). Se trata de un recurso que normalmente reaparece en la mayoría de los textos de estos autores una vez comienzan a utilizarlo.

${ }^{6}$ Así lo califica, por ejemplo, Sanz Villanueva (2015).
} 
como Javier Cercas, Rafael Reig, David Trueba o Antonio Orejudo.

Dicho esto, podemos extraer al menos dos consecuencias de la nómina recién comentada: (1) el fenómeno de la novela multimodal difícilmente puede considerarse como una práctica de vanguardia fruto de un prurito de ruptura o experimentación; y (2) el análisis de este fenómeno permite trascender las fronteras de la obra individual de un autor, así como de las propuestas de un grupo, generación o conjunto de autores con una estética coincidente. El primer punto requiere alguna matización adicional, ya que parece ser directamente contrario a la idea, muy generalizada, que Gibbons (2012) recoge explícitamente en su capítulo en el Routledge Companion on Experimental Literature. Gibbons se dedica justamente a mostrar las vías de experimentación que la novela multimodal hace posibles.

La tesis que aquí pretendo argumentar es que la multimodalidad permite, en efecto, abrir las puertas a la búsqueda de nuevas maneras de narrar una historia y, en esa medida, es un recurso potencialmente experimental. Sin embargo, esto no es un rasgo inherente al fenómeno. A menudo se emplea de una forma convencional que no genera la opacidad, la ruptura de esquemas o la búsqueda estética sorprendente que sería esperable de un recurso de experimentación novelesca. Al contrario, se suma a la práctica más usual en la comunicación humana (en el diálogo con otras personas, en la prensa, la televisión, internet...), en donde la mayoría de mensajes se trasladan recurriendo a un compuesto de diversos modos semióticos sin que esto suponga ningún desafío particular para la comprensión o desciframiento del mensaje. La siguiente sección desarrolla esta idea.

\section{LA MULTIMODALIDAD COMO COMPLEMENTO DEL TEXTO}

Toda imagen, gráfico, diagrama, recorte, fórmula matemática o juego tipográfico interactúa con el texto al que acompaña. Esto es, todos 
los modos semióticos presentes en una novela se comentan mutuamente en la medida en la que forman una unidad (la novela) a la que el lector trata de dar sentido. Con independencia de este principio general, en ocasiones los elementos no verbales - más a menudo las imágenes- se configuran como refuerzo directo de una descripción verbal. Se trata por tanto de una écfrasis a la que le acompaña la imagen comentada. Esto plantea el problema de si la segunda está realmente integrada en la narración, o si por el contrario es más bien superflua o redundante. Elijo como ejemplo paradigmático de esta práctica dos novelas de Javier Marías que me parecen especialmente nítidas al respecto, Todas las almas y Tu rostro mañana, donde se reproduce una fotografía del escritor John Gawsworth (Marías, 2006: 119) y varios carteles distribuidos durante la Segunda Guerra Mundial (Marías, 2002: 292-293), respectivamente. El tipo de interacción que el texto mantiene con las imágenes queda representado en el siguiente pasaje:

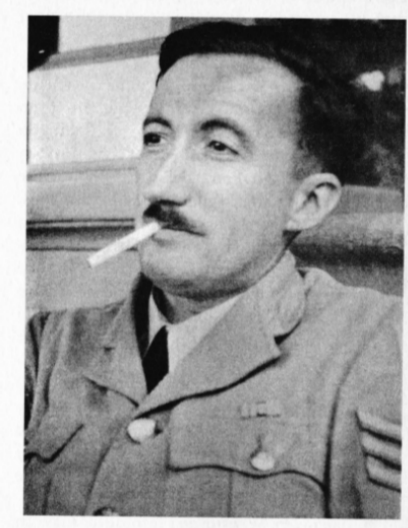

En esa única foto que he visto lleva el uniforme de la RAF y tiene en los labios un cigarrillo aún no encendido. [...]. Es un rostro generoso. La mirada limpia. La oreja es llamativa. Podría estar escuchando. [...]. La ironía en la mirada es muy parecida la la de CromerBlake], pero la de Gawsworth es más afable, no hay en ella ningún rastro de sarcasmo ni cólera, ni su anuncio, ni su posibilidad siquiera. El uniforme no está bien planchado (Marías, 2006: 119).

Figura 4. Todas las almas, de Javier Marías (2006: 118). 
A la écfrasis, con la consiguiente etopeya que lleva aparejada, se le suma, en la página enfrentada, la propia fotografía. De este modo, el lector puede captar y comprobar por sí mismo las cualidades descritas, añadiéndose, tal vez, una dimensión más vívida y evocadora de la figura del escritor en cuestión o, tal vez, matices que la descripción no recoge. Lo que me interesa destacar de ello es que es un uso de la multimodalidad que no sigue los patrones descritos en Hallet (2009) o en Gibbons (2014) en la medida en la que, ciertamente, "it is an intrinsic part of the fictional world" (Hallet, 2015: 638) y responde directamente a un fragmento del texto, pero no está conectada con el progreso de la narración, ni con una ruptura de la linealidad narrativa, ni necesitamos tomarla en consideración para entender cómo avanza la historia. La decodificación e integración de los otros lenguajes que constituyen la obra está ya elaborada en el propio texto, que adjunta su fuente visual como complemento y prueba de los comentarios. No obstante, la inclusión de la fotografía responde también a lo que Mitchell (1994: 28) llama "the resistance of the icon to the logos". Esto es, la idea de que la traducción verbal de las imágenes (la écfrasis) conlleva siempre una potencial pérdida de contenido, o una manipulación. Por eso, la multimodalidad es algo más que un complemento o un adorno que remite, aunque sea de forma indirecta, a los límites del lenguaje para captar la realidad que el narrador pretende describir y para generar un discurso veraz (tema, por cierto, recurrente en la obra de Marías). En consecuencia, implica siempre un carácter meta-referencial más o menos explícito que ha sido de hecho uno de los rasgos más estudiados del fenómeno (Maziarczyk, 2013).

De aquí se sigue otro rasgo que considero importante introducir en el análisis de cualquier forma de multimodalidad literaria: la permutabilidad de los elementos multimodales. Dicho en pocas palabras, se trata de comprobar si cambiarlos de posición altera o no su significado. Si sucede lo primero, el elemento en cuestión resulta no permutable; si ocurre lo segundo, será permutable. Esto permite constatar que los estudios en 
este campo tienden a privilegiar los textos cuyos elementos no verbales son no permutables, dado que esto se percibe como una imbricación más genuina con el discurso verbal. Sin embargo, ha de tenerse presente que hay ocasiones en las que la aparición unas páginas antes o después del elemento en cuestión no supone un cambio sustancial respecto de su sentido dentro de la obra, y que no por ello la novela es multimodal en menor medida. Anclada a la écfrasis que la comenta, la fotografía de Gawsworth podría aparecer al final del capítulo, o al principio del mismo, lo cual no supondría una alteración sustancial de su función en la obra. Evidentemente, se trata del caso contrario al de los ejemplos de Jardiel Poncela que hemos mencionado, caracterizados por la no permutabilidad de los elementos multimodales: si el reloj aparece en otro momento, la temporalidad de la narración cambia; si el texto se oscurece dos páginas después, ya no puede vincularse con la oscuridad del túnel o de la noche.

Además de establecer una importante distinción entre los elementos multimodales permutables y no permutables, la fotografía de John Gawsworth apunta otro rasgo muy importante de la multimodalidad que no se ha subrayado lo suficiente. La multimodalidad y, especialmente, la inclusión de imágenes, refuerza la impresión de realidad. Estas reclaman, con independencia de que sea verdad o no, que los hechos o sujetos que vemos existieron fuera del libro, y la prueba de ello es que los vemos. Dicho de otro modo, "As a record of what has been, they appear to testify to the 'truth' of a past moment" (Doloughan, 2011: 32). "Photographs, documents and physical objects are regarded as indices of a real, empirical world" (Hallet, 2009: 145). Por ello, esto no es una ruptura del pacto de ficción, sino una estrategia para generar verosimilitud y vincular el texto con un contexto externo a la página. De ahí que quepa comparar este fenómeno con la no ficción y con otros géneros narrativos no ficcionales como la autobiografía o la crónica, habitualmente propensos a una multimodalidad que acredite e ilustre los hechos con imágenes y documentos. De ahí, también, que las novelas que se fingen documentos 
verídicos, como Cabaret Biarritz ${ }^{7}$, tiendan a ser multimodales. Zilcosky lo explica con claridad al estudiar la narrativa de viajes de carácter ficcional:

Postmodern travel writers such as Sebald deliberately incorporate this fact / fiction anxiety into their works by including photographs of train tickets, passports, and people, as if to prove that their journeys "really" happened, only later to report that they found some of these artifacts in flea markets. (Zilcosky, 2008: 9).

Más allá de que la narración ficcional presente o no un viaje, la multimodalidad genera siempre una ansiedad o indeterminación entre lo factual y lo ficcional. Incluso en los casos en donde las fotografías parecen superfluas o redundantes. Así, puede decirse que la multimodalidad de Todas las almas no es un mero complemento accesorio, sino que aporta un significado a la construcción del relato que va más allá de las palabras que describen el rostro de John Gawsworth.

\section{LA MULTIMODALIDAD COMO NARRACIÓN PARALELA}

Además de una multimodalidad integrada en la narración pero desvinculada de su progresión, la narrativa española de las últimas décadas nos permite observar recursos más vinculados con las estrategias propiamente narrativas que más han interesado a críticos como Gibbons (2010) o Nøorgard (2010). Pero la estrategia en la que quiero centrarme aquí es un tanto particular, y no ha sido recogida por estos autores. Es la que denomino un uso de la multimodalidad como narración paralela. Para desarrollar esta idea, tomo dos novelas españolas representativas, a saber:

\footnotetext{
${ }^{7}$ La novela se presenta como la recopilación y edición que un filólogo contemporáneo ha hecho de materiales y documentos relativos a una serie de sucesos misteriosos acontecidos en Biarritz en el verano de 1925.
} 
La torre herida por el rayo, de Fernando Arrabal, y La música del mundo, de Andrés Ibáñez. El fenómeno que describo es el siguiente: un lenguaje no verbal se alterna con el discurso verbal a lo largo de toda la obra o de una parte de ella, generando una progresión de acontecimientos que transcurre paralela y en la que las dos series de hechos comunicados por los dos modos semióticos avanzan simultáneamente. En el primer caso, una partida de ajedrez representada mediante la sucesión de movimientos sobre el tablero se alterna con la narración verbal de distintos episodios del pasado y presente de los dos jugadores. En la segunda novela, diversos fragmentos de la partitura del movimiento adagio de la Octava Sinfonía de Bruckner se alternan con la narración verbal de los acontecimientos que van presenciando los protagonistas al adentrarse en un espacio simbólico llamado praderabruckner. Ambos modos son narrativos, puesto que comunican una sucesión de acontecimientos en el tiempo (ya de movimientos en el tablero, ya de sonidos).

La idea fundamental es que los tableros de ajedrez y la partitura forman una única entidad continua, una sucesión de acontecimientos ordenados (la partida o la sinfonía que representan) que tiene sentido en sí misma. Esta continuidad narrativa a lo largo de los elementos multimodales de la novela no está presente en las obras de Danielewski, Safran Foer, Haddon o Auster que más se han analizado, en donde la gran riqueza de recursos multimodales empleados no tiene la autonomía que supone las narraciones paralelas, sino que está incrustada o fusionada en el texto, desprovistos del cual no tendrían sentido. En La torre herida por el rayo, la representación gráfica de la partida de ajedrez es totalmente autónoma, hasta el punto que la novela puede leerse como comentario de ella. Como una explicación no ya técnica, sino psicológica y simbólica de cada jugada. Además, en tanto que partida de ajedrez, la novela parte de la idea del dualismo que representa este juego, algo que la alternancia de dos modos semióticos refuerza desde un nivel visual. 
- Estoy más cerca del gusano revoltón, de la avispa, de la hormiga, de la termita, del piojo, del mosquito, de la cigarra. Y aunque no lo crea, la luciérnaga me ha iluminado siempre mucho más que Dios.

- No habla como una «criadan.

- Todo lo que sé, me lo enseñó mi tío. Desde los nombres de las estrellas hasta la metamorfosis del caballito del diablo. Desgraciadamente murió, y tuve que venirme a Valencia a servir.

Soledad no creía en el pecado. Pero le estaba haciendo pecar. Con el pensamiento. Y quizás también con el deseo. Tarsis decidió súbitamente no volver a ver al Padre Benito al que no podría confesar la noche que pasaba con Soledad.

- Ya no puedo volver a la Compania. Mañana me marcho para Francia. No seré jesuita.

- Si se va a Francia... me animo y me voy yo también. ¿Puedo acompañarle?

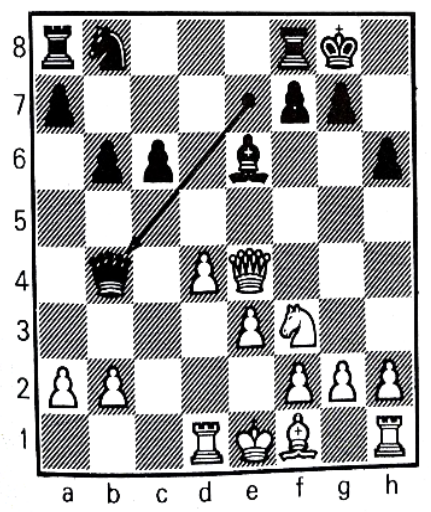

143

Figura 5. La torre herida por el rayo, de Fernando Arrabal (1983: 143)

Lo que sucede a lo largo de la novela es que los dos modos se comentan entre si $^{8}$. La consecuencia de lo que se narra verbalmente (relativo a las vidas de los dos jugadores) tiene su correspondencia en los movimientos en el tablero. El tablero, a su vez, para quien sepa leerlo, es

\footnotetext{
${ }^{8}$ Adicionalmente, la novela contiene un tercer elemento multimodal importante. Se trata de la carta de tarot que da título a la novela y que se reproduce en la primera página. La novela es un desarrollo de la carta de tarot inicial que le da título. Esto es, un modo semiótico como comentario del otro modo semiótico principal que contiene la obra. A su vez, este entrecruzamiento de modos traza una equivalencia con el otro modo semiótico que abre y titula la novela. Este fenómeno se asemeja más al que representa, por ejemplo, La invención de la soledad, de Paul Auster, en donde una imagen genera y simboliza el conjunto de la narración verbal.
} 
el reflejo de los dos mundos interiores en lid. Muestra la conjunción de psicología, política, poder y sexualidad que la novela tiene como tema principal (Podol, 1986: 263). Algunos ejemplos de ello son el triunfo de Tarsis, que se corresponde con la revelación final (en la última línea de la novela, a modo de jaque mate) de que Amary era el niño francés a quien Tarsis jugó a convertir en su esclavo cuando iban a la escuela. Se trata, por tanto, de un doble sometimiento que se da de forma paralela en las dos narraciones. Igualmente, el movimiento de ataque de la reina a b4 (Arrabal, 1983: 143) puede leerse como símbolo del paso decisivo y sin retorno que toma el protagonista al abandonar su vocación religiosa. $\mathrm{O}$, en la misma línea, el fracaso de Amary cuando la partida parecía decantarse a su favor (Arrabal, 1983: 196) tiene como correlato su fracaso en la intriga política de la novela, ya que se le desenmascara como secuestrador del ministro ruso, que desde el comienzo sabemos en cautiverio. Conviene advertir que no hay una correspondencia directa entre cada secuencia verbal y cada movimiento en la partida. Se trata más bien de que ambos lenguajes apuntan hacia una serie de rasgos comunes de los protagonistas que se van construyendo y mostrando de forma progresiva y paralela.

Pero la tensión narrativa se genera también en buena medida a través de la narración multimodal. Queremos saber quién gana y queremos saber cómo van superando o cayendo en los obstáculos y celadas que el rival tiende a lo largo de la partida. El ajedrez es una intriga autosuficiente, pero, entremezclado con el discurso verbal, acaba también siendo la narración de las respectivas vidas de los dos contendientes, así como un retrato poliédrico de su psique. Y es esta interrelación multimodal lo que sin duda otorga un mayor grado de originalidad e interés a la novela.

Ahora bien, lo que se ha denominado narración paralela no es exclusiva de una partida de ajedrez, sino que puede realizarse a través de diversos recursos multimodales. Por ejemplo, a través de la interrelación del discurso verbal y de la partitura musical que tiene lugar en La música del mundo, de Andrés Ibáñez. La narración verbal se construye como correlato de la partitura reproducida. Cada elemento de la partitura tiene 
una correspondencia en el jardín por el que pasean los protagonistas, convertido en una suerte de espacialización de la música y de su progresión temporal.

volvieron de nuevo a la entrada

-ya vais viendo cómo funciona esto... la música nos conduce a la entrada de nuevo... ahora podemos pasear por el jardín.. en principio, haremos el mismo recorrido que antes - aunque quizá en esta ocasión lleguemos a otro lugar...

„paseo por el jardín...

»y, de nuevo, el motivo que conduce a lo alto del escalón de mármol

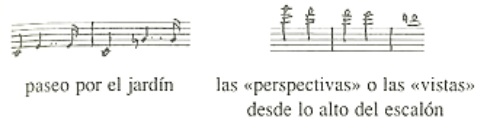

-hemos repetido, pues, el mismo recorrido que antes, dijo Otón cuando los tres estaban de nuevo en lo alto del escalón... hemos venido desde la puerta, caminando a través de la hierba, hemos subido el escalón... pero ahora sucederá algo diferente, ya que nada puede repetirse nunca exactamente igual... escuchad esa melodía de la trompa: nos conduce ahora hacia el fondo del jardín... y ahora, la melodía de los violoncelos:

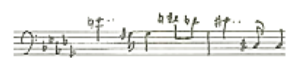

»es una melodía muy cromática, muy modulante... sugiere la vegetación algo insana, húmeda, caprichosa, del fondo del jardín... es decir, las centáureas

ahora caminaban por entre las plantas de río, las húmedas y azuladas centáureas... eran casi tan altas como ellos; sus hojas, taladradas por hambrientos escarabajos, ondeaban en las alturas o reptaban por la tierra...

-recordad esta melodía (6), dijo Otón, la melodía del fondo del jardín... la melodía de la niebla, del río, del misterio, de las centáureas

ahora sonaban tristes melodías en tono menor

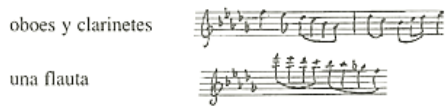

que junto con el tema sensual y cromático (6) definían la doble naturaleza de los lugares húmedos y misteriosos: su cualidad
(4)

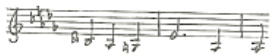

volvían, caminando al lado del seto... de nuevo frente a puerta blanca

- la melodía que vamos a oír a continuación, señala el principio del verdadero PASEO POR LA PRADERA... es una melodía en los violines... señala la entrada en la pradera... así se entra en la pradera.

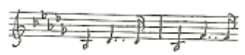

entraron de nuevo; caminaban lentamente, cruzando la pradera en dirección al escalón central como las criaturas de un sueño

- ¿escucháis? ahora subimos el escalón... ahora ya estamos arriba... desde aquí casi hay perspectiva... vistas...

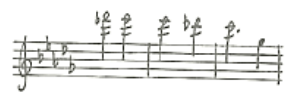

los tres habían subido al escalón de mármol... sonaba ahora la que, según Otón, era la música de la nueva altura - y les pedía incluso que «oyeran», en la música que sonaba, ese mismo punto de vista más elevado que los tres acababan de alcanzar con sólo subir a lo alto del escalón

sonaban de nuevo los temas del principio, que Otón había re. lacionado con los setos del jardín, los límites naturales

- escuchad, decía obsesivamente... de nuevo el estremecimiento inicial (1), que nos conduce, en una secuencia que ya nos es familiar, al tema de los dos árboles, la armonía de la creación (3)... antes sonaba en la mayor... ahora, añadió con una sonrisa traviesa, estamos un poco más altos... suena un tono entero más alto: en si mayor... sin embargo, es una armonía imperfecta, sin raíz... en el bajo no se oye la tónica, la nota básica del acorde, sino la tercera: la primera inversión del acorde... el hombre, liberado de la piedra, quiere saltar al ángel — no llega... la idea de una profunda escisión en la cadena del ser...

"y ahora, escuchad, suena de nuevo el motivo de la entrada en el jardín (4)...

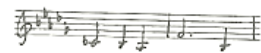

Figura 6. La música del mundo, de Andrés Ibáñez (1995: 164-165).

\section{Leer aquí implica no solo una integración de modos semióticos}

para seguir la narración, sino su superposición; supone rastrear las analogías existentes entre la progresión del discurso verbal y el no verbal. El narrador facilita en parte la tarea al establecer varias correspondencias, 
como el motivo del paseo por el jardín o las perspectivas desde lo alto del escalón que se mencionan en la página 165. Este tipo de equivalencias manifiestas son una marca del paralelismo al que me refiero, son una pauta explícita del tipo de interacción multimodal que se está produciendo. No estamos, entonces, ante una narración que alterna la información transmitida mediante el lenguaje verbal y la que nos llega a través de otros modos semióticos, sino que ambos modos discurren simultáneamente y avanzan de la mano: las notas del pentagrama por un lado, el paseo de los personajes por otro. Lo más significativo de este recurso es que no puede identificarse con un comentario a la manera en la que un narrador describe lo que puede verse en una fotografía, como sucedía en Todas las almas. No es un comentario de lo que se ve en la partitura ni de sus propiedades técnicas, sino que la narración verbal es el contenido imaginario que se le atribuye a la música, la supuesta historia que esta narra en su progresión. El despliegue de ambos lenguajes en paralelo genera una correlación entre el avance de uno y el del otro. Así, la narración verbal ha de leerse como la imitación de la música que la partitura codifica, el paseo de los tres personajes por la praderabruckner es el adagio de la Octava de Bruckner. La interacción entre los dos modos presentes busca entonces recrear la experiencia de audición de esta obra, es decir, busca recrear un medio (la música) en otro (la literatura).

Lo que me interesa destacar es que la multimodalidad implica en estos casos el desarrollo de una narración que transcurre en paralelo a su correlato verbal. Ambas son autónomas, pero establecen una interacción clave para la construcción del significado de la novela. El paseo por el jardín de los protagonistas de La música del mundo no tiene sentido narrativo si no se entiende como una recreación de los distintos elementos de la música que la partitura codifica. Y, también, como una forma de dar entidad física y espacial a la música y a la lógica alternativa que esta representa en la novela, tema crucial, tal y como señala Lozano Mijares (2006). Igualmente, la caracterización psicológica que la partida de ajedrez implica no es traducible al discurso verbal, ya que lo que este último dice, 
aquella lo muestra, adquiriendo connotaciones que sin su contraparte verbal no serían posibles y que constituyen el principal logro de la obra. Por ello, suponen una matización necesaria a la idea de que, en estas novelas, "word and image act in synchronicity, engaged in the production of a shared textual meaning" (Gibbons, 2010: 101). En un primer nivel, ambos discursos pueden verse como independientes y, por tanto, no actúan en sincronicidad. Ahora bien, su inclusión en la misma novela, en la misma obra, nos obliga a interpretarlos conjuntamente y a darles un significado que integre los diversos modos en acción.

\section{LA MULTIMODALIDAD COMO ABRASIÓN}

El dibujo de las tres formas de integración aparentemente conflictiva del discurso multimodal se completa con un fenómeno al que denomino la multimodalidad como abrasión. Tomo este último término de la teorización de Daniel Albright (2014: 211) para caracterizar la interacción entre dos medios que se dan simultáneamente dentro de una obra artística. Se trata, por tanto, de un uso ampliado del concepto, ya que en la multimodalidad literaria la simultaneidad no es posible del mismo modo en el que lo es en, por ejemplo, una película en la que la imagen y la música transcurren a la vez y el espectador recibe ambos estímulos también al mismo tiempo.

La contigüidad se da cuando los dos medios parecen apuntar en una misma dirección (por ejemplo, dice Albright, cuando vemos los helicópteros de guerra en Apocalypse Now y suenan las Valquirias de Wagner), mientras que la abrasión se produce cuando los dos medios parecen apuntar en direcciones opuestas, generando un efecto de choque o aparente incompatibilidad que también se explota estéticamente (como cuando Fellini hacer sonar esa misma música de Wagner en una escena en la que unas señoras mayores toman un té). En el caso de las novelas multimodales, hablaremos de abrasión cuando el elemento no verbal choque o entre en contradicción con la información que recibimos a través del lenguaje verbal. Para ello desarrollo, de nuevo, dos ejemplos 
de la narrativa española contemporánea que representan con claridad el fenómeno: Los inmortales, de Manuel Vilas, y de El hacedor (de Borges) Remake, de Agustín Fernández Mallo.

Los inmortales contiene numerosos elementos multimodales. Destaca en la novela la tendencia a incluir imágenes de los personajes famosos que se mencionan con frecuencia a lo largo de ella (el Arcipreste de Hita, Robespierre o Dostoievsky, por ejemplo). Esto ha sido criticado en diversas reseñas ("una especie de novela pop ilustrada con fotos caprichosas", Sanz Villanueva, 2012), ya que la mayoría de ellas aparece como complemento no de una écfrasis, sino de la mera mención de los distintos individuos y se percibe como gratuita. Pero es un recurso que acerca la novela a la estética de los formatos textuales digitales, donde lo habitual es encontrar este tipo de imágenes que muestran uno de los retratos o fotografías más difundidos de la persona aludida (igual que sucede en las solapas de los libros). Cerca ya del final de la novela, este principio se modifica sustancialmente. Virgil y Fede (Virgilio y Federico García Lorca) pasean por la playa, donde se encuentran con tres veraneantes llamados José María Aznar, Felipe González Márquez y Leticia Ortiz Rocasolano (Vilas, 2012: 166-167). 
166

Siguieron paseando por Cambrils. Caminaron por el puerto. Se fueron hasta el faro. El mar estaba tranquilo. Cambrils parecía un paraíso. Todos los turistas estaban felices y sonrientes. Había mujeres hermosas en todas las terrazas. Mujeres alemanas, que medían uno ochenta, rubias y resplandecientes. Calzaban un 43. Parecían varones secretos.

- Siempre he creído que éste sobra - dijo Vírgil, señalando el mar con el dedo índice-. Su finalidad es recordarnos el Terror. Y eso que yo lo amo profundamente. Amo el mar, claro. Es hermosísimo. Pero sobra. No era necesaria su presencia. Con los ríos hubiera sido suficiente. La creación del mar es un extravío de la inteligencia de los dioses. No te apures, Fede, a los inmortales se nos permite criticar a los dioses, si es que existen.

Siguieron paseando y Vírgil fue adivinando el nombre y la fecha de defunción de todos los turistas con quienes se fueron, azarosamente, encontrando:

Primer turista: José María Aznar López, nacido en Madrid el 15 de septiembre de 1959, morirá en Madrid en 2049.

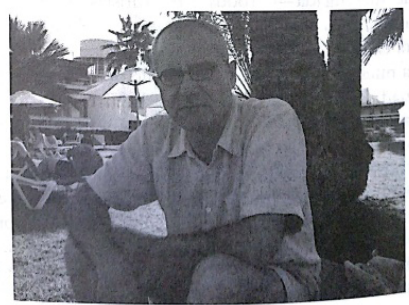

Segundo turista: Felipe González Márquez, nacido en Madrid el 9 de febrero de 1965, morirá en Madrid en 2061

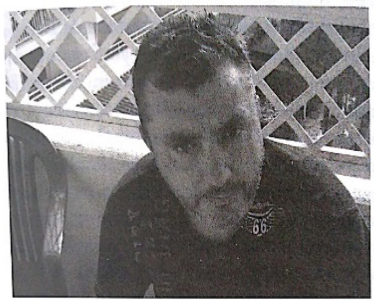

Tercer turista: Letizia Ortiz Rocasolano, nacid en Barcelona en 1976, morirá en Barcelona en 2073.

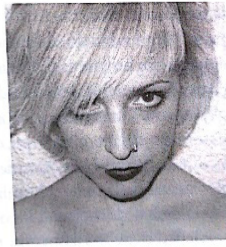

Vírgil se quedó pensativo y dijo: «Es un tanto aburrido esto de la adivinación en España, tu querido país, Fede, pues casi todo el mundo ha nacido o en Madrid o en Barcelona y la longevidad es ya pura rutina biológica, una longevidad de derechas, diría yo;

Figura 7. Los inmortales, de Manuel Vilas (2011: 166-167).

Las fotografías no permutables que acompañan a la mención de cada uno de estos personajes, sin embargo, chocan frontalmente con la expectativa del lector. Todo el que comparta el contexto cultural apropiado será consciente de que la imagen y el texto apuntan a individuos muy distintos, generando una sorpresa que constituye uno de los mecanismos expresivos que la novela pone en juego. Los individuos retratados sencillamente no son los que el texto nombra. Pero esto no lo dice ni el texto ni la imagen, sino el entrecruzamiento de ambos. La abrasión puede tener efectos y funciones muy diversas en diferentes obras. En este caso, se suma al sentido del humor particular y heterodoxo que se despliega durante todo el libro y al tipo de broma desmitificadora a la que el autor es proclive. Además, abunda en el componente autoficcional del texto, uno 
de cuyos personajes es "el escritor español Manuel Vilas (1962-2051)" (Vilas, 2011: 195), autor de obras que llevan el mismo título que las que el autor empírico ha publicado. Esto se debe a que la segunda fotografía, correspondiente a Felipe González Márquez, es la del propio Manuel Vilas (autor empírico). La novela no señala este hecho en ningún momento, si bien el rostro puede identificarse con facilidad, no solo porque hayamos visto o buscado imágenes del autor a través de internet u otros medios, sino porque en la solapa del libro podemos encontrar una foto del autor en donde se aprecia con claridad que se trata del mismo individuo que responde al nombre de un expresidente del gobierno. Además, es un recurso que Vilas ya había empleado en España, tal y como analiza Gómez (2015). Juego autoficcional o simple broma, lo que aquí me interesa destacar es que la relación entre los modos semióticos presentes es de mutua abrasión. Hay una incompatibilidad en sus respectivos contenidos que se construye a partir del hecho de que la fotografía se entiende como una ampliación del texto, como una presentación no lingüística del individuo aludido.

El hacedor (de Borges) Remake, de Agustín Fernández Mallo, presenta otra coyuntura que deriva también hacia el choque de los modos semióticos en juego. Como el título evidencia, el libro es una reescritura de la obra homónima de Borges y, en tanto que tal, mantiene la estructura externa y los títulos de todas las piezas. En la primera parte de Mutaciones, narración más extensa de la obra de Mallo (no de la de Borges), un narrador en primera persona emprende un viaje por Passiac, condado estadounidense en Nueva Jersey, siguiendo los pasos del artista Robert Smithson, que realizó ese mismo viaje equipado con una cámara de fotos que dio testimonio de ello, en 1967. 


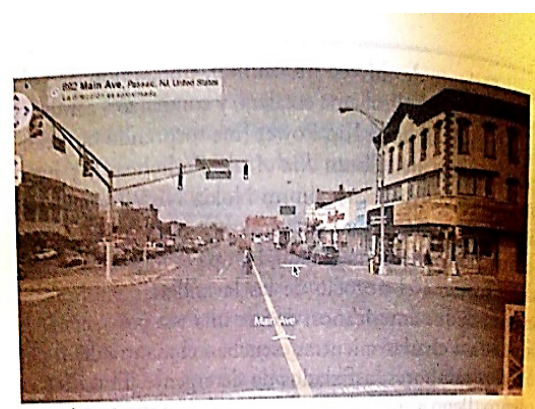

Fotografia n. 08

Finalmente el camión toma el desvio hacia la derecha (foro n. 9); por algún motivo eso me alivia. El camión se pierde mientras a lo lejos veo la majestuosa M de McDonald's, su familiaridad representa para mí un alivio añadido.

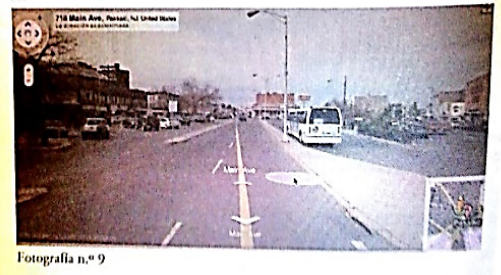

En ese momento giro sobre mis talones, $y$ veo un edificio en el que no habbia reparado, relativamente alo y antiguo, $y$ reconozco al momento una foto que hizo Smithson, una panorámica de la calle.

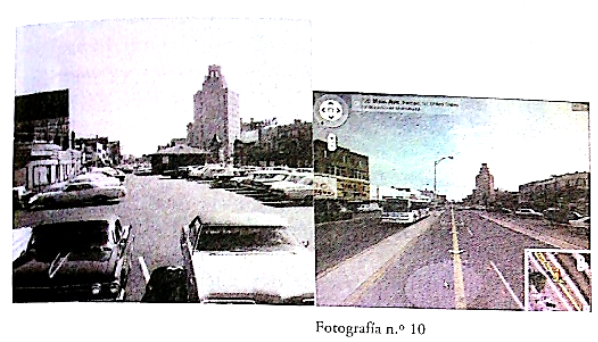

Bajo el asfalto de esta calle, afirma Smithson, se encuentra una vieja vía de tren que divide a la ciudad en dos. También dice que ese aparcamiento de la foto es un monumento que divide a la ciudad en dos, como si fuera un espejo. Disparo mi cámara (foto n. ${ }^{\circ} 10$ ).

Salvo ese edificio alto del fondo y sus casas adyacentes, todo ha cambiado. Pero, de alguna manera, tengo la sensación de que todo sigue igual, como si la personalidad de un lugar la otorgaran las fotografías, como si las fotografías valieran no para distinguir y clasificar épocas sino para buscar la constante de una ecuación quc involucra al tiempo y al carácter. De alguna manera, mi fotografía y la de Smithson, me digo, son también espejo la una de la otra.

TERCERA PARADA: GOLDEN COACH DINER

El sol ha vuelto a salir, bebo un trago de agua, continúo caminando hacia el Golden Coach Diner, la $3 .^{\text {il }}$ parada de Robert Smithson, mientras releo el artículo original, en el que él afirma:

\section{8}

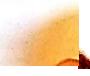

69

Figura 8. El hacedor (de Borges), Remake, de Agustín Fernández Mallo (2011: 68-69).

A las fotos que Smithson tomó en 1967 se le van añadiendo las que toma el narrador del relato, a la vez que comenta lo que ve y a dónde va dirigiendo sus pasos. Esto, en sí mismo, sería la base de una narración multimodal que contrastaría dos conjuntos de fotografías dispuestas a medida que la narración verbal progresa. Pero hay algo más. Mientras que el discurso verbal presenta el viaje como un desplazamiento físico, real, del narrador, a través del territorio descrito, las imágenes dinamitan esta idea. "Preparo el material, me aseguro de que el teléfono móvil tiene suficiente batería como para hacer una buena colección de fotos de la caminata" (Fernández Mallo, 2011: 58). Conforme lee, el lector no puede 
evitar preguntarse qué caminata es esa, ya que el narrador está sentado frente a su ordenador y las imágenes que presenta son fotos que muestran la pantalla de este y que corresponden a Google Earth. Y, aún más, cómo es posible la interacción con un vigilante que se describe unas páginas después:

Intento dar un paso al frente y veo que no puedo, una línea amarilla en el asfalto, en la que pone Main Ave, parece organizar el tránsito de peatones [...], y me impide ir más allá, atravesarla. No es un aviso, no es una prohibición, en una imposibilidad física, como si un "campo antihumanos" me repeliera cada vez que intento aproximarme. Un tipo que está al otro lado de la línea, junto a un camión, un vigilante, supongo, me mira y me dice que mi intento es vano, que ni desde que él está ahí, ni antes, alguien ha conseguido traspasar esa línea. Sólo la pueden traspasar objetos, no personas, me dice” (Fernández Mallo, 2011: 72).

El diálogo con este individuo se prolonga en algunos párrafos posteriores, hasta el punto de que el vigilante "se ríe de mí con grandes carcajadas" (Fernández Mallo, 2011: 73). Esto implica una interacción del narrador con el personaje que las fotografías contradicen, ya que, como es evidente, no es posible establecer ningún diálogo con los paseantes de las calles congeladas de Google Earth. Por otro lado, la descripción verbal de la situación es deliberadamente ambigua: procede en todo momento de forma que ambos planos de la experiencia (el del viaje que implica un desplazamiento físico y el del viaje a través de Google Maps y Google Earth) puedan solaparse. Continuar, girar sobre los propios talones, descender, confundirse de camino o dar un paso al frente son verbos que tienen sentido desde las dos perspectivas. La consecuencia de esto es que la experiencia digital a través de la interfaz parece fusionarse con la experiencia corporal. La tecnología se incorpora al sujeto, se presenta como una extensión de su 
cuerpo y de sus sentidos. Lo que aquí pretendo, no obstante, no es tanto profundizar en esta idea, que nos llevaría muy lejos de los objetivos de este trabajo, sino mostrar cómo la multimodalidad y el choque entre la información que transmiten los distintos modos en juego está anclada en el núcleo de la propuesta estética de la obra, que continuamente percute intentando desestabilizar nuestra percepción de lo que es real y lo que no, así como poner en jaque la identificación de lo virtual con lo irreal o inexistente, siguiendo de este modo la estela de las pesquisas metafísicas borgeanas. El relato desarrolla una abrasión continua entre la narración del viaje y las imágenes del mismo matizada por los indicios textuales que nos muestran que el narrador está frente a su ordenador (sería aún más violenta si en ningún momento el discurso verbal apuntara a esta circunstancia). Y asimilar este choque no es algo accesorio: remite al núcleo de la poética del autor, esto es, está totalmente integrado en la construcción del sentido del texto.

\section{CONCLUSIONES}

Este trabajo ha puesto de manifiesto tres casos en los que se plantean dificultades para integrar la multimodalidad con la narración lingüística. En el primero, por su aparente redundancia; en el segundo, por su independencia y desarrollo paralelo; en el tercero, por el choque y conflicto que se genera entre lo visual y lo verbal. Recurriendo a un modo de expresión gestual muy habitual en la comunicación humana, puede decirse que en el primer caso la multimodalidad parece limitarse a asentir al modo verbal; en el segundo, encogerse de hombros ante él y desarrollarse por su cuenta; en el tercero, negar con vehemencia.

Ahora bien, se ha mostrado asimismo que esto no significa que los modos no lingüísticos estén desligados del modo lingüístico dominante, dado además que la búsqueda de unificación de los diversos estímulos e información es una herramienta fundamental en la interpretación de una obra, a la que el lector busca dar sentido de manera global. Ninguno de 
los casos de multimodalidad analizados resulta superfluo, ya que todos implican una ruptura de la linealidad de la lectura en un doble sentido. En uno literal, obliga a una atención que rompe la sucesión de líneas iguales y niveladas que habitualmente constituye la lectura de un texto. Al incluir una imagen, o un diagrama, o una tipografía distinta, la novela deja de ser un encadenamiento de elementos semejantes para requerir, también, otro tipo de atención. Además, en un sentido figurado, la interpretación deja de basarse en la sucesión totalmente ordenada y preestablecida de signos homogéneos y requiere que el lector realice una síntesis creativa, asignando el lugar o la parte del texto a la que afecta la multimodalidad, así como el tipo de relación que guarda con ella. Por eso, la noción de permutabilidad que se ha expuesto es particularmente importante para el análisis de cualquier elemento multimodal concreto.

Varias cuestiones surgen de la problemática desarrollada: ¿qué otras estrategias y formas de relación entre los modos se dan dentro de una novela en un sentido más amplio?, ¿es posible trazar una taxonomía de ello? Por otro lado, ¿puede argumentarse que alguna de estas obras pone en cuestión cuál de los modos es el predominante?, Además, en tanto que parte de la ficción narrativa, la multimodalidad es susceptible de un análisis narratológico. La cuestión de quién narra los elementos multimodales es un aspecto que requiere mayor desarrollo crítico.

Asimismo, este artículo permite realizar una primera cala en el análisis de la multimodalidad en los diferentes universos narrativos de los distintos autores españoles que la practican. En este sentido, se trata de un fenómeno que podría incluirse en las líneas de la narrativa española contemporánea que señalan autores como Gracia y Ródenas (2011). A la vez, se ha buscado desvincular el fenómeno de estéticas, escuelas o autores concretos, tratando de poner de manifiesto su diversidad y carácter global e intergeneracional. A la luz de todo esto, parece claro que la novela multimedial no es una moda, ni tampoco el producto de un prurito vanguardista minoritario y circunscrito a unos pocos autores.

Finalmente, cabe afirmar que todas estas cuestiones nacen de la 
nueva lectura que este trabajo permite hacer de la afirmación de Baldry y Thibault:

Multimodal text integrate selections from different semiotic resources to their principles of organization. [...] These resources are not simply juxtaposed as separate modes of meaning making but are combined and integrated to form a complex whole which cannot be reduced to, or explained in terms of the mere sum of its separate parts (Baldry y Thibault: 2006: 18).

Las novelas desarrollan formas y estrategias para separar los "modos de generar sentido", o para enfrentarlos entre sí, o para que parezcan redundantes, pero el resultado sigue siendo el mismo, esto es, su integración en un todo que es más complejo que la suma de sus partes y que no puede explicarse solo a través del análisis de estas. Este trabajo ha mostrado distintas vías para plantear un enfoque conjunto, incidiendo en cómo se da la paradoja de que su aparente choque es parte de su integración, su pretendida desconexión, una estrategia de engranamiento.

\section{REFERENCIAS BIBLIOGRÁFICAS}

ALBRIGHT, D. (2014). Panaesthetics. On the Unity and Diversity of the Arts. New Haven and London: Yale UP.

ARRABAL, F. (1983). La torre herida por el rayo. Barcelona: Destino.

BALDRY A. \& THIBAULT, P. J. (2006). Multimodal Transcription and Text Analysis. Londres y Oakville: Equinox.

BATEMAN, J.; WILDFEUER, J. \& HIIPPALA, T. (2017). Multimodality: Foundations, Research and Analysis. A Problem-Oriented Introduction. Berlín y Boston: De Gruyter Mouton.

DOLOUGHAN, F. J. (2011). Contemporary Narrative. Textual 
Production, Multimodality and Multiliteracies. Londres y Nueva York: Continuum.

FERNÁNDEZ MALLO, A. (2011). El hacedor (de Borges). Remake. Madrid: Alfaguara.

GIBBONS, A. (2010). "I Contain Multitudes: Narrative Multimodality and the Book that Bleeds". En New Perspectives on Narrative and Multimodality, Ruth Page (ed.), 99-114. Londres y Nueva York: Routledge.

(2012). "Multimodal literature and experimentation". En The Routledge Companion to Experimental Literature, Joy Bray, Alison Gibbons y Brian McHale (eds.), 420-434. Londres y Nueva York: Routledge.

(2014). Multimodality, Cognition, and Experimental Literature. Londres y Nueva York: Routledge.

GÓMEZ, S. (2015). "Juegos autoficcionales en la obra de Manuel Vilas". Pasavento. Revista de Estudios Hispánicos 3.1, 155-169.

GRACIA, J. y RÓDENAS, D. (2011). Historia de la literatura española. 7. Derrota y restitución de la modernidad 1939-2010. Madrid: Crítica.

GRECO, B. (2014). L'umorismo parodico di Enrique Jardiel Poncela. I romanzi. Alessandria: Edizioni dell'Orso.

GUELBENZU, J. M. ${ }^{a}$ (1977). El mercurio, Ana Rodríguez Fischer (ed.). Madrid: Cátedra.

HALLET, W. (2008). "Visual Culture und Literatur: Multimodale Romane, Literaturunterricht und Literaturdidaktik". FLuL-Fremdsprachen Lehren und Lernen 37, 141-153.

(2009). "The Multimodal Novel: The Integration of Modes and Media in Novelistic Narration". En Narratology in the Age of Cross-Disciplinary Narrative Research, Sandra Heinen y Roy Sommer (eds.), 129-153. Berlín y Nueva York: Walter de Gruyter. (2015). "Non-verbal Semiotic Modes and Media in the Multimodal Novel. En Handbook of Intermediality: Literature - Image - 
Sound-Music, Gabriele Rippl (ed.), 637-651. Berlín y Boston: De Gruyter.

IBÁÑEZ, A. (1995). La música del mundo. Barcelona: Seix Barral.

JARDIEL PONCELA, E. (1989). La tournée de Dios. Madrid: Biblioteca Nueva.

(1990). Amor se escribe sin hache. Madrid: Cátedra.

(1992). ¡Espérame en Siberia, vida mía! Madrid: Cátedra.

JEWITT, C. (2014). "Introduction to Part I". En The Routledge Handbook of Multimodal Analysis, Second Edition, Carey Jewitt (ed.), 11-14. Londres y Nueva York: Routledge.

(ed.) (2014). The Routledge Handbook of Multimodal Analysis, Second Edition. Londres y Nueva York: Routledge.

JEWITT, C., BEZEMER, J. \& O'HALLORAN, K. (2016) Introducing Multimodality. Londres y Nueva York: Routledge.

KRESS, G. (2009). Multimodality: A Social Semiotic Approach to Contemporary Communication. Londres y Nueva York: Routledge. KRESS, G. y LEEUWEN, T. (2001). Multimodal Discourse: The Modes and Media of Contemporary Communication. Londres: Hodder Arnold.

LOZANO MIJARES, M.P. (2006). “Andrés Ibáñez o la novela española posmoderna”. Revista de Literatura 68.135, 221-246.

MAZIARCZYK, G. (2013). "From Metareference to Storytelling: Multimodality in Contemporary American Fiction”. Roczniki Humanistyczne 61, 281-295.

MARÍAS, J. (2006). Todas las almas. Madrid: Debolsillo. (2002). Tu rostro mañana 1, Fiebre y lanza. Madrid: Alfaguara.

MITCHELL, W. J. T. (1994). Picture Theory: Essays on Verbal and Visual Representations. Chicago y Londres: University of Chicago Press. MODE (2012). Glossary of multimodal terms. Disponible en línea: https:// multimodalityglossary.wordpress.com/ [01/03/2018].

MUSSETTA, M. (2014). "Semiotic Resources in The Curious Incident of the Dog in the Night-Time: The Narrative Power of theVisual in 
Multimodal Fiction". MATLIT 2.1, 99-117.

(2016). "La Ficción Multimodal: breve recorrido teórico y principales supuestos actuales”. En De la imaginación a la representación, Cecilia Saleme (ed.), 100-122. Bahía Blanca, Argentina: Editorial de la Universidad Nacional del Sur.

NØRGAARD, N. (2010). "Multimodality and the Literary Text. Making Sense of Safran Foer's Extremely Loud and Incredibly Close". En New Perspective on Narrative and Multimodality, Ruth Page (ed.), 115-126. Londres y Nueva York: Routledge.

PAGE, R. (2010). "Introduction". En New Perspective on Narrative and Multimodality, Ruth Page (ed.), 1-13. Londres y Nueva York: Routledge.

(ed.) (2010). New Perspective on Narrative and Multimodality. Londres y Nueva York: Routledge.

PODOL, P. L. (1986). "Chess as Plot, Theme and Structure: Fernando Arrabal's La torre herida por el rayo". Hispania 69.2, 262-266.

RAJEWSKY,I.O.(2005). “Intermediality, Intertextuality, and Remediation: A Literary Perspective on Intermediality”. Intermédialités 6, 43-64. RÍOS, J. (1992). Larva. Barcelona: Mondadori.

RIPPL, G. (ed.) (2015). Handbook of Intermediality. Literature - Image - Sound - Music. Berlín y Boston: De Gruyter.

SANZ VILLANUEVA, S. (2002). "Los inmortales. Manuel Vilas". El Cultural. Disponible en línea: http://www.elcultural.com/revista/ letras/Los-inmortales/30406 [01/03/2018].

VILAS, M. (2009). Aire Nuestro. Madrid: Alfaguara. (2012). Los inmortales. Madrid: Alfaguara.

VILLEGAS, J. C. (2012). "Hibridación genérica, digresión y autorreferencialidad en la obra de Roberto Bolaño". En Metanarrativas hispánicas, Marta Álvarez, Antonio J. Gil González y Marco Kunz (eds.), 11.24. Münster: LIT.

WOLF, W. (2013). "(Inter)mediality and the study of literature". En Digital Humanities and the Study of Intermediality in Comparative 
Cultural Studies, Steven Tötösy de Zepetnek (ed.), 19-31. West Lafayette: Purdue Scholarly Publishing Services. (2002). "Intermediality Revisited: Reflections on Word and Music Relations in the Context of a General Typology of Intermediality". En Word and Music Studies: Essays in Honor of Steven Paul Scher and on Cultural Identity and the Musical Stage, Suzanne M. Lodato, Suzanne Aspden, Walter Bernhart (eds.), 13-34. Amsterdam: Rodopi.

(1999). The Musicalization of Fiction. A Study in the Theory and History of Intermediality. Ámsterdam y Atlanta: Rodolpi.

ZILCOSKY, J. (2008). "Writing Travel”. En Writing Travel. The Poetics and Politics of the Modern Journey, John Zilcosky (ed.), 3-21. Toronto, Buffalo y Londres: University of Toronto Press.

Recibido el 18 de abril de 2018.

Aceptado el 6 de junio de 2018. 